\title{
Mutation in position of 32 ( $G>U)$ of S2M differentiate human SARS-CoV2 from Bat Coronavirus
}

Majid Vahed ${ }^{1,2}$, Mohammad Vahed ${ }^{3}$, Aaron Sweeney ${ }^{4}$, Farshad H Shirazi ${ }^{1,2}$, Mehdi Mirsaeidi ${ }^{5 *}$

${ }^{1}$ Pharmaceutical Sciences Research Center, Shahid Beheshti University of Medical Sciences, Niayesh Highway, Valiasr Ave, Tehran, Iran

2Department of Toxicology/Pharmacology, School of Pharmacy, Shahid Beheshti, University of Medical Sciences, Niayesh Highway, Valiasr Ave, Tehran, Iran

${ }^{3}$ Department of Computational Medicine and Bioinformatics, University of Michigan, Ann Arbor, MI, 48105, USA

${ }^{4}$ Department of Medicine, School of Medicine, McGill University, Montreal, Quebec, Canada

${ }^{5}$ Division of Pulmonary, Critical Care, Sleep and Allergy, Department of Medicine, Miller School of Medicine, University of Miami, Miami, FL, United States

\section{Corresponding Authors:}

Mehdi Mirsaeidi MD,

Division of Pulmonary and Critical Care,

University of Miami

1600 NW 10th Ave \# 7072B, Miami, Florida, USA 33136

msm249@med.miami.edu

\section{Author's Contributions}

$\mathrm{MaV}, \mathrm{MoV}, \mathrm{FSH}, \mathrm{MM}$ contributed to the acquisition, analysis, and interpretation of data, MaV, and MoV drafted of the manuscript. MaV, MoV, AS, FSH, MM contributed to the conception of study, interpretation of data, and critical revision.

Running title: S2M motif of SARS-CoV19 


\section{ABSTRACT}

The new Severe Acute Respiratory Syndrome Coronavirus 2 (SARS-CoV-2) is a zoonotic pathogen that has rapidly mutated and become transmissible to humans. There is little existing data on the mutations in SARS-CoV-2 and the impact of these polymorphisms on its transmission and viral load. In this study, the SARS-CoV-2 genomic sequence was analyzed to identify variants within the 3'UTR region of its cis-regulatory RNA elements. A 43-nucleotide genetic element with a highly conserved stem-loop II-like motif (S2M), was discovered. The research revealed $32 \mathrm{G}>\mathrm{U}$ and $16 \mathrm{G}>\mathrm{U} / \mathrm{A}$ mutations located within the $\mathrm{S} 2 \mathrm{M}$ sequence in human SARS-CoV-2 models. These polymorphisms appear to make the S2M secondary and tertiary structures in human SARS-CoV-2 models less stable when compared to the S2M structures of bat/pangolin models. This grants the RNA structures more flexibility, which could be one of its escape mechanisms from host defenses or facilitate its entry into host proteins and enzymes. While this S2M sequence may not be omnipresent across all human SARS-CoV-2 models, when present, its sequence is always highly conserved. It may be used as a potential target for the development of vaccines and therapeutic agents.

Keywords: SARS-CoV-2; Zoonotic; S2M motif; RNA folding, UTR region. 


\section{Introduction}

The emergence of new viral pathogens is a danger to public health (1). Three emerging pathogenic coronaviruses (CoVs), Severe Acute Respiratory Syndrome Coronavirus (SARS-CoV-1), Middle East Respiratory Syndrome Coronavirus (MERS-CoV), and a newly identified CoV (SARS-CoV-2), are zoonotic viruses, which utilize bats as their natural reservoir. They are then transmitted through intermediate hosts, eventually infecting humans. The pressure on host selection of SARS-CoV-2 in human models will have an effect on long term conservation of mutations that enhance its transmissibility (2). However, the determinants regulating strong trans-species evolution remain unknown due to challenges in recognizing viral precursors and animal reservoirs (3). A 43-nucleotide genetic element with a highly conserved stem-loop II-like motif (S2M) has been reported in four groups of positive single stranded RNA viruses; Astroviridae, Picornaviridae, Caliciviridae, and Coronaviridae (4).

The significance of S2M sequences in viral strains remains to be determined. However, it appears to be important to viral transmissibility and will likely be found in future emergent coronaviruses (5). Given that S2M is a highly conserved component of coronaviruses viral genome and is absent from the human genome, it could become a potential target for antiviral drug therapy (6). This study was performed in order to analyze coronavirus genomic sequences isolated from human, bat, and pangolin models in order to identify variants within the structured cis-regulatory RNA elements in the 3'UTR region, including the S2M loop.

\section{Methods}

\subsection{Calculation of Allele Frequency and Occupancy}

The SARS-CoV-2 isolated from patients on a cruise ship in Japan (NCBI GenBank Accession Number LC528232.1) was used as a reference genome. Identifying functional RNA motifs and elements was performed using RegRNA 2.0 tools (filtered to human settings) (7). 
The S2M motifs (43 nucleotides long) were aligned for bat/pangolin models (Fig. 1 (a)) and for human models SARS-COVs (Fig. 1 (b)). A G to $U$ amino acid transfer at position 32 and a $G$ to U/A amino acid transfer as position 16 (Fig. 1(b)) were found in human SARS-CoV-2. This profile was used to search for all viral sequences in GenBank, while using different combinations of 32 $\mathrm{G}>\mathrm{U}$ and $16 \mathrm{G}>\mathrm{U} / \mathrm{A}$ nucleotide substitutions that occur in a conserved region within $3^{\prime} \mathrm{UTR}$, known as the S2M motif.

\subsection{Quantifying Similarities between Motifs and Structures}

RNA sequences were aligned using 3'UTR $(29,543-29,903)$, with queries in a BLASTn search of the NCBI database for S2M motifs(8, 9). The $3^{`}$ UTR stem-loop structures were determined by using the RNAfold web server (http://rna.tbi.univie.ac.at/forna/). Additionally, sequence and structural information of astrovirus S2M motifs was integrated for RNAfold design to analyze a potential zoonotic precursor for coronaviruses from a hypothetical infectious sequence (10). The PDB structure for S2M was downloaded from the Protein Data Bank (http://www.rcsb.org/pdb) (PDB ID: 1XJR) (6). All of the structures were visualized by PyMOL (11) and analysis was performed as presented in previous studies $(12,13)$. RNAComposer was used to model the three dimensional (3D) RNA structures $(14,15)$. Clustal Omega was used to apply mBed algorithms for guide trees. ClustalW alignment tools were used to execute multiple sequence alignments (16). The S2M RNA sequences were compared between members of the coronavirus family (bat and pangolin CoVs, SARS-CoV-1, and SARS-CoV-2) as well as the astrovirus family (avian, porcine, bovine, chicken, turkey, ovine, mink, tiger, human and mamastrovirus). The S2M motifs were screened with miRBase tools in order to identify potential miRNA binding sites (17).

\subsection{Identification of Single Nucleotide Substitutions in the SARS-CoV-2 Genome}


Only alignment positions which harbored defined A/T/G/C residues in $95 \%$ of their genomes were considered for nucleotide substitutions (18). In order to be graphically represented, sequence logos of the selected S2M motifs were then constructed using WEBLOGO (19-21).

A nucleotide BLAST search of these sequence motifs was performed on the NCBI portal. S2M containing sequences were identified for the following sequence:

\section{5'-TTTCA (G>U/A)CGAGGCCACGCGGAGTACGATCGAG(G>U)GTACAGTGAA(U>C)-3'.}

This text string profile was used to search for all the viral sequences in GenBank available as of August $14^{\text {th }}, 2020$, while using different combinations of the aforementioned nucleotide substitutions. A phylogenetic tree was created by generating a genomic epidemiological map of SARS-CoV-2 at position 29724 (S2M) using NextStrain tools (https://nextstrain.org/) (22). The sequences of the different isolates were obtained from GISAID (https://www.gisaid.org/) (23).

\section{Results}

\subsection{Calculation of Allele Frequency and Occupancy}

Position 32 of $\mathrm{S} 2 \mathrm{M}$ is a critical point of the sequence that is specific to the human coronaviruses and variable for the bat/pangolin coronaviruses (Fig. 1 (a,c)). A second polymorphism appears in human SARS-CoV-2 models at position 16 G>U/A (Fig. 1 (d)). A previous polymorphism was found in SARS-CoV-1 at position $6 \mathrm{C}>\mathrm{U}$ (Fig. 1 (b)).

\subsection{Calculation of Cis-Regulatory RNA structures and Minimum Free Energy}

Rapidly emerging variations within the cis-regulatory RNA structures of the SARS-COV-2 genome were analyzed and characterized. The hotspot of S2M motif mutations was found to occur at position $32(\mathrm{G}>\mathrm{U})$, where a single mutation occurred between bat/pangolin and human stem-loop structures. 
The impact of $32 \mathrm{G}>\mathrm{U}$ mutations decreased RNA secondary structure stability in both MFE (-8.80 kcal $/ \mathrm{mol}$ vs. $-6.20 \mathrm{kcal} / \mathrm{mol})$ and centroid structures $(-8.80 \mathrm{kcal} / \mathrm{mol} \mathrm{vs} .-0.80 \mathrm{kcal} / \mathrm{mol})$ when using RNAfold calculations (Fig. 2). The $16 \mathrm{G}>\mathrm{U}$ mutations in SARS-CoV-2 improved RNA secondary structure stability in both minimum free energy (MFE) $\quad(-8.80 \mathrm{kcal} / \mathrm{mol} \mathrm{vs} .-11.70$ $\mathrm{kcal} / \mathrm{mol})$ and centroid structures $(-8.80 \mathrm{kcal} / \mathrm{mol}$ vs. $-9.90 \mathrm{kcal} / \mathrm{mol})$ when using RNAfold calculations (Fig. 2).

Interestingly, the MFE and centroid secondary S2M structures of SARS-CoV-2_2020 are significantly different from human and bat/pangolin coronaviruses. As shown in Fig. 2, the $G>U$ base changes at residues 16 and 32 influence the folding of hairpin loops.

Additional analysis of canonical and MFE S2M steam-loop structures is shown by the dot plot (Fig. 3). By superimposing various mountain plots, the bat/pangolin S2M secondary structures appear to show equal distribution on both sides. However, the SARS-CoV-2 S2M secondary structures shows non-uniform distribution (Fig. 3). The closer the two curves, the better is the defined diffraction of the S2M structures in human and bat/pangolin coronaviruses.

The centroid structures of RNA S2M sequences with minimal base-pair distance are significantly different in human MFE structures of astroviruses, and are similar in other astroviruses (Fig. S3, S4).

\subsection{The Tertiary Structures of SARS S2M RNA}

3D structures of S2M sequences of coronaviruses in human and bat/pangolin models were created based on the secondary structure in the dot-bracket format (Fig. 4). The mutations at position 16 and $32(G>U)$ impact tertiary structures and consequently cause conformational changes. The human stem-loop structure is bent to the right side when compared to the stem- 
loop structure in the bat/pangolin coronavirus (Fig. 5). The conformational changes within the S2M loop may affect its binding to host proteins and enzymes.

\subsection{Alignment and Clustering of S2M Stem-Forming Elements and Columns}

ClustalW multiple sequence alignment was used to align secondary structures.

The great majority of the sequences were able to fold into the canonical S2M stem-loop structure. Clusters of S2M sequences are highlighted. The clustering trees of coronavirus (Fig. 6) and astrovirus (Fig. S2) are displayed. The $32 \mathrm{G}>\mathrm{U}$ mutation introduces changes in Watson-Crick pairing, with resultant changes in the predicted secondary structures. ClustalW multiple sequence alignment reveals that $32 \mathrm{G}>\mathrm{U}$ base-pairing exhibits complementary changes to the secondary structures.

\subsection{Potential Interaction of S2M motifs and Human miRNAs}

Mirbase was used to screen human miRNA that could target S2M sequences. Additional focus was put on miRNAs that have been reported as components of anti-viral miRNA-mediated defense [28]. This study identified two potential binding sites within the S2M sequences of bat/pangolin and SARS-CoV-1: hsa-miR-1304-3p \& hsa-miR-1307-3p. Only one potential binding site was found within the S2M of Australian and Iranian SARS-CoV-2 samples: hsa-miR-1307-3p (Fig. 7).

\subsection{Earlier mutations of $16 \mathrm{G}>\mathrm{U} / \mathrm{A}$ S2M motifs}


While analyzing all available sequences available up to August $14^{\text {th }} 2020$, a 16 G>U/A S2M motif mutation was identified at position 29742 of SARS-CoV-2-2020 in Iran, Australia, Taiwan, Sir Lanka, Bahrain, USA, Georgia, Bangladesh, Norway, Hong-Kong, Germany and Turkey (Fig. 8 and 9).

\section{Discussion}

The current study found that a consistent $G>U$ mutation at the 32 position, of the 43 nucleotide, long S2M sequence of SARS-CoV-2. This mutation has not been found in any bat or pangolin CoV strains. We concluded that transmissibility to human from bat/pangolin was related to this mutation.

The MFE ${ }^{1}$ and centroid secondary structures were found to be significantly different in SARS-CoV-2 sequences in comparison to bat/pangolin coronavirus sequences. This appears to be due to the mutation occurring at position 32 of S2M. There were also significant differences in the $\mathrm{MFE}^{1}$ and centroid structures between the human SARS-COV-2 and SARS-COV-2_2020 S2M sequences. The MFE and centroid secondary structures were observed to be similar in S2M bat/pangolin coronavirus and SARS-COVs.

Ancestral recombination and genetic similarity between coronaviruses infecting bats/pangolins and humans may have played a key role in the evolution of the strain that led to the introduction of SARS-CoV-2 in humans (24).

The analysis of Australian SARS-CoV-2 sequences revealed clustering of mutations in S2M secondary structures across coronaviruses and astroviruses. These new changes within the S2M sequences and structures could be the virus' escape mechanism from host defense systems. The SARS S2M secondary structures containing G (16), and G (32) are conserved in Bat/pangolin related coronaviruses. A/U (16) and $U$ (32) mutations are found in SARS-COV-22020. These changes create a less stable RNA structure in SARS-CoV-2, thereby granting it 
more flexibility, which could be one of its escape mechanisms from host defenses or facilitate its entry into host proteins and enzymes

Based on the structural similarities between micro RNA hairpins implicated in gene regulation, it is possible that S2M functions through an RNA interference-like mechanism, and possibly targeting homologous sequence loci in the infected organisms (25).

$32 \mathrm{G}>\mathrm{U}$ mutations may change the RNA secondary structures that are critical to viral reproduction or interfere with sequences targeted by host miRNAs. While screening for human miRNA targets on S2M motifs, two targets sequences were found within the bat/pangolin and SARS-CoV-1 S2M and one within the SARS-CoV-2. The presence of host miRNA targets within S2M motifs may be crucial for host selection and anti-viral miRNA-mediated defense. The S2M of SARS-CoV-2 may promote its viability and infectivity.

It is likely that the S2M sequences of (+) SSRNA viruses are still active and will continue to affect these viruses' evolution [5]. The $16 \mathrm{G}>\mathrm{U} / \mathrm{A}$ and $32 \mathrm{G}>\mathrm{U}$ nucleotide changes in the S2M sequence of SARS-CoV-2 render it a target for one human miRNA, hsa-miR-1307-3p. However, bat/pangolin coronavirus and SARS-CoV-1 S2M sequences are targetable by two human miRNAs hsa-miR-1307-3p and hsa-miR-1304-3p. As such, only one human miRNA is capable of targeting the S2M sequence of SARS-CoV-2 and affecting its viral replication.

\section{Conclusions}

The study examined S2M mutations able to impact the cis-regulatory elements in the SARS-CoV-2 genome. While the evolutionary and functional origin of S2M has yet to be discovered, its presence across even distantly related viruses insinuates that the sequence is important for viral transmission. These findings provide insight into the significance of viral RNA structures and introduce S2M as a potential target for development of vaccines and therapeutic agents. 
bioRxiv preprint doi: https://doi.org/10.1101/2020.09.02.280529; this version posted September 8, 2020. The copyright holder for this preprint (which was not certified by peer review) is the author/funder, who has granted bioRxiv a license to display the preprint in perpetuity. It is made available under aCC-BY-ND 4.0 International license.

\section{Acknowledgments}

Authors would like to that Nextstrain for providing a real-time snapshot of evolving SARS-CoV2.

\section{Conflict of interest}

The authors declare no conflict of interest. 


\section{References}

1. Weiss RA, and McMichael AJ. Social and environmental risk factors in the emergence of infectious diseases. Nat Med. 2004;10(12 Suppl):S70-6.

2. Totura AL, and Baric RS. SARS coronavirus pathogenesis: host innate immune responses and viral antagonism of interferon. Curr Opin Virol. 2012;2(3):264-75.

3. Webby R, Hoffmann E, and Webster R. Molecular constraints to interspecies transmission of viral pathogens. Nat Med. 2004;10(12 Suppl):S77-81.

4. Tengs T, Kristoffersen AB, Bachvaroff TR, and Jonassen CM. A mobile genetic element with unknown function found in distantly related viruses. Virol J. 2013;10:132.

5. Tengs T, and Jonassen CM. Distribution and Evolutionary History of the Mobile Genetic Element s2m in Coronaviruses. Diseases. 2016;4(3).

6. Robertson MP, Igel H, Baertsch R, Haussler D, Ares M, Jr., and Scott WG. The structure of a rigorously conserved RNA element within the SARS virus genome. PLoS Biol. 2005;3(1):e5.

7. Chang TH, Huang HY, Hsu JB, Weng SL, Horng JT, and Huang HD. An enhanced computational platform for investigating the roles of regulatory RNA and for identifying functional RNA motifs. BMC Bioinformatics. 2013;14 Suppl 2:S4.

8. Altschul SF, Gish W, Miller W, Myers EW, and Lipman DJ. Basic local alignment search tool. $J$ Mol Biol. 1990;215(3):403-10.

9. Camacho C, Coulouris G, Avagyan V, Ma N, Papadopoulos J, Bealer K, et al. BLAST+: architecture and applications. BMC Bioinformatics. 2009;10:421.

10. Lorenz R, Bernhart SH, Honer Zu Siederdissen C, Tafer H, Flamm C, Stadler PF, et al. ViennaRNA Package 2.0. Algorithms Mol Biol. 2011;6:26.

11. Seeliger D, and de Groot BL. Ligand docking and binding site analysis with PyMOL and Autodock/Vina. J Comput Aided Mol Des. 2010;24(5):417-22.

12. Vahed M, Sweeney A, Shirasawa H, and Vahed M. The initial stage of structural transformation of Abeta42 peptides from the human and mole rat in the presence of $\mathrm{Fe}(2+)$ and $\mathrm{Fe}(3+)$ : Related to Alzheimer's disease. Comput Biol Chem. 2019;83:107128.

13. Vahed M, Neya S, Matsuzaki K, and Hoshino T. Simulation Study on Complex Conformations of Abeta42 Peptides on a GM1 Ganglioside-Containing Lipid Membrane. Chem Pharm Bull (Tokyo). 2018;66(2):170-7.

14. Antczak M, Popenda M, Zok T, Sarzynska J, Ratajczak T, Tomczyk K, et al. New functionality of RNAComposer: an application to shape the axis of miR160 precursor structure. Acta Biochim Pol. 2016;63(4):737-44.

15. Popenda M, Szachniuk M, Antczak M, Purzycka KJ, Lukasiak P, Bartol N, et al. Automated 3D structure composition for large RNAs. Nucleic Acids Res. 2012;40(14):e112.

16. Madeira F, Park YM, Lee J, Buso N, Gur T, Madhusoodanan N, et al. The EMBL-EBI search and sequence analysis tools APIs in 2019. Nucleic Acids Res. 2019;47(W1):W636-W41.

17. Griffiths-Jones S, Saini HK, van Dongen S, and Enright AJ. miRBase: tools for microRNA genomics. Nucleic Acids Res. 2008;36(Database issue):D154-8.

18. Mishra A. PAK, Gupta P., Pradhan P., Dhamija S., et al. Mutation landscape of SARS-CoV-2 reveals three mutually exclusive clusters of leading and trailing single nucleotide substitutions. bioRxiv 2020.

19. Crooks GE, Hon G, Chandonia JM, and Brenner SE. WebLogo: a sequence logo generator. Genome Res. 2004;14(6):1188-90.

20. Schneider TD, and Stephens RM. Sequence logos: a new way to display consensus sequences. Nucleic Acids Res. 1990;18(20):6097-100.

21. Vahed M, Ishihara JI, and Takahashi H. DIpartite: A tool for detecting bipartite motifs by considering base interdependencies. PLoS One. 2019;14(8):e0220207. 
22. Hadfield J, Megill C, Bell SM, Huddleston J, Potter B, Callender C, et al. Nextstrain: real-time tracking of pathogen evolution. Bioinformatics. 2018;34(23):4121-3.

23. Elbe S, and Buckland-Merrett G. Data, disease and diplomacy: GISAID's innovative contribution to global health. Glob Chall. 2017;1(1):33-46.

24. Li X, Giorgi EE, Marichann MH, Foley B, Xiao C, Kong XP, et al. Emergence of SARS-CoV-2 through Recombination and Strong Purifying Selection. bioRxiv. 2020.

25. Kofstad T, and Jonassen CM. Screening of feral and wood pigeons for viruses harbouring a conserved mobile viral element: characterization of novel Astroviruses and Picornaviruses. PLoS One. 2011;6(10):e25964. 
(a) Bat/pangolin-COVs (56)

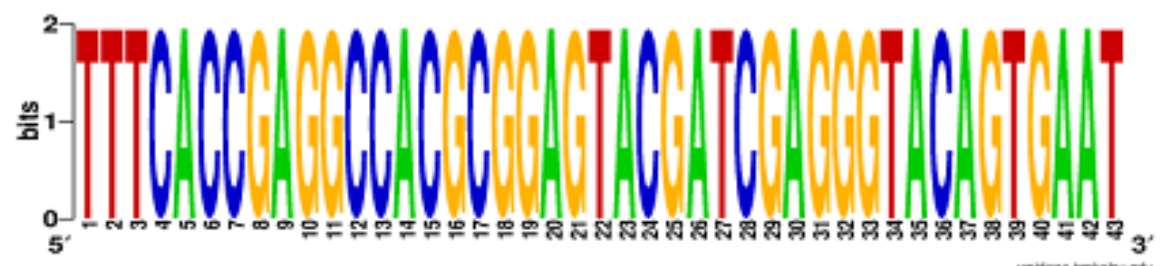

(b) SARS-COVs (210)

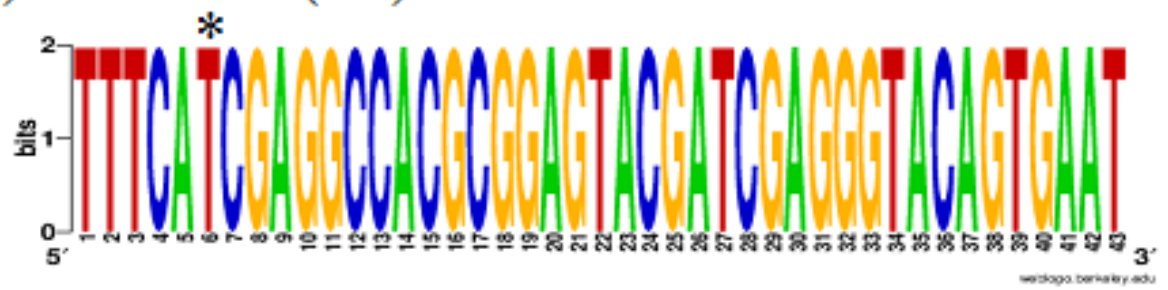

(c) SARS-COV2-2019(13725)

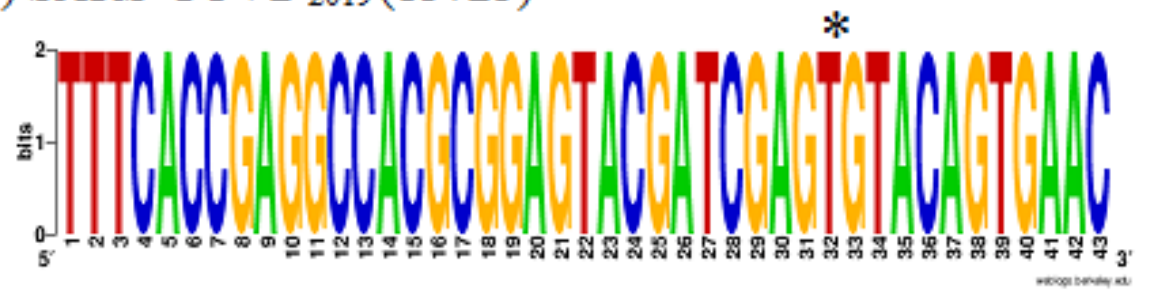

(d) SARS-COV2-2020 (183)

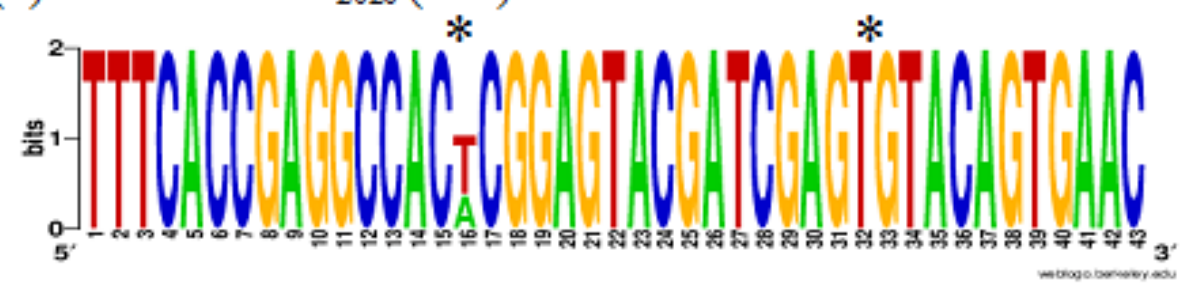

Figure 1. Multiple sequence alignment logos of selected S2M motifs. (a) BLASTn search of the NCBI database for G32 S2M motifs (b) Human U32 S2M coronavirus motifs. Nucleotide letter heights indicate their frequency at the G32 position in bat and pangolin S2M hairpins. 

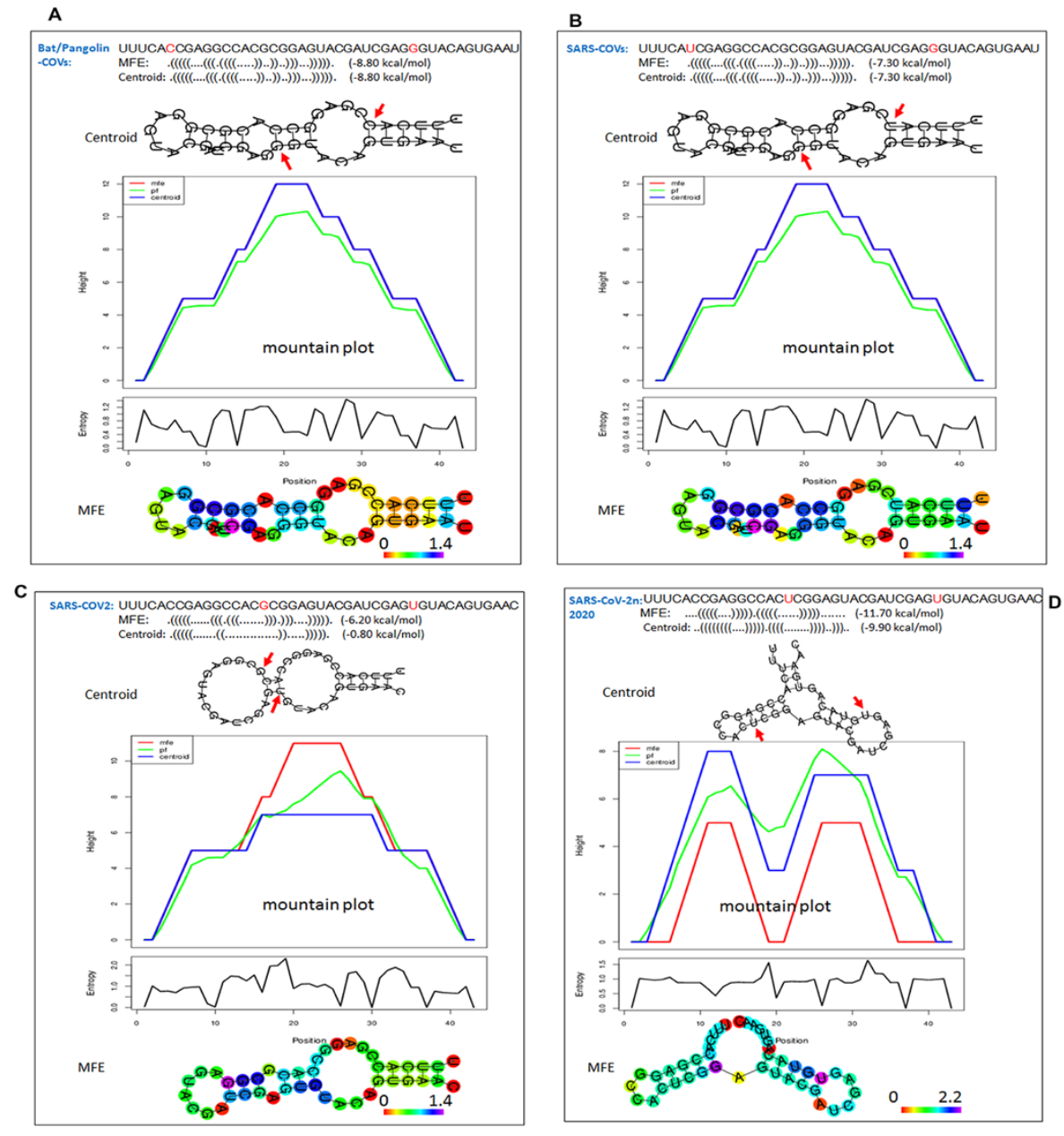

Figure 2. The minimum free energy structure (MFE) and centroid structures for S2M motifs. Base pairs are colored according to base pair probabilities computed with thermodynamic parameters using the Vienna Program $[12,13]$. The mountain plot is an $x y$-graph that represents secondary structures including MFE, thermodynamic ensemble of RNA (pf), and centroid structures in a plot of height versus position. "MFE" represents the minimum free energy structure, "pf" indicates partition function and "centroid" represents the centroid structure. The height $m(k)$ is given by the number of base pairs enclosed at position k. Three curves are shown: the MFE structure (red), the pairing probabilities (black) and a positional entropy curve (green). Well-defined regions are identified by low entropy. (b) Structural changes where $G$ is substituted by $U$. The positional entropy is coded by hues ranging from red (low entropy, well-defined) to violet (high entropy, illdefined). The lower panel depicts entropy vs position. 
A

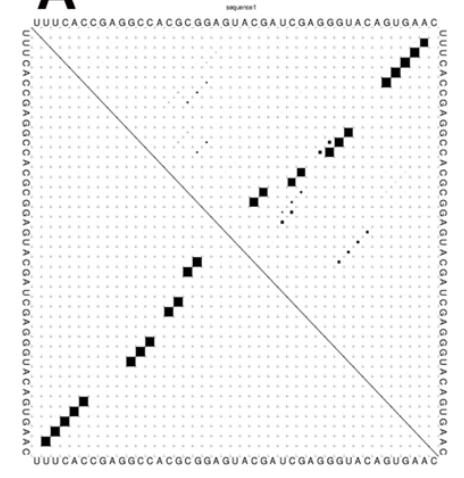

C

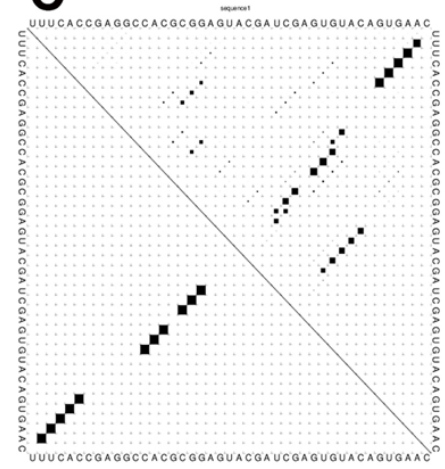

B

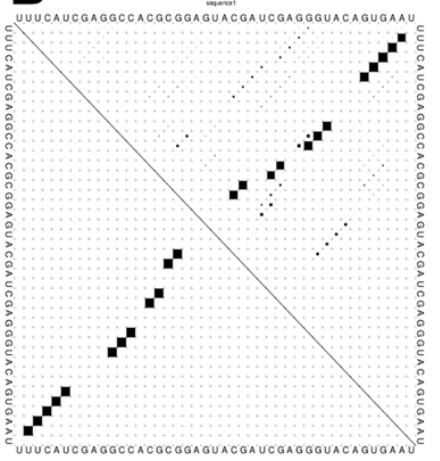

D

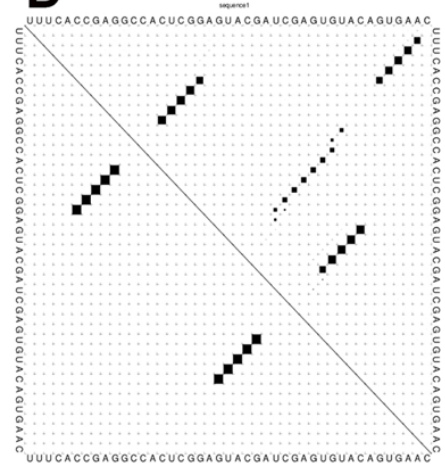

Figure 3. Dot plot produced by RNAfold. The MFE structure is represented in the lower left triangle. The probability of all possible base pairs is represented in the top right triangle. The area of each dot is proportional to the pairing probability of the base pairs. (a) Human coronavirus S2M, (b) Bat/pangolin coronavirus S2M. The resulting plot depicts three curves. The red curve shows two peaks derived from the MFE structure, the black curve demonstrates pairing probabilities, and the green curve indicates positional entropy. Every dot symbolizes a base pair. The size of the dots in the upper right triangle is proportional to the respective base pairing probability. Changes in the MFE structure of human coronavirus S2M in the lower left triangle. 


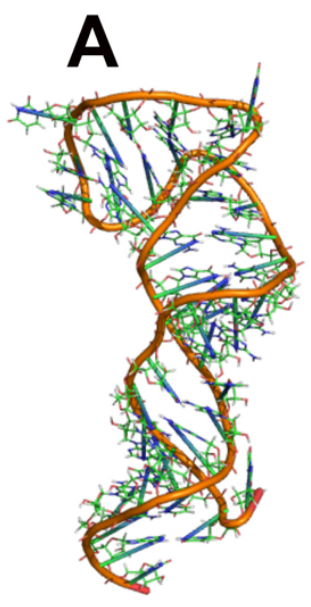

S2M Bat/Pangolin COVs

MFE

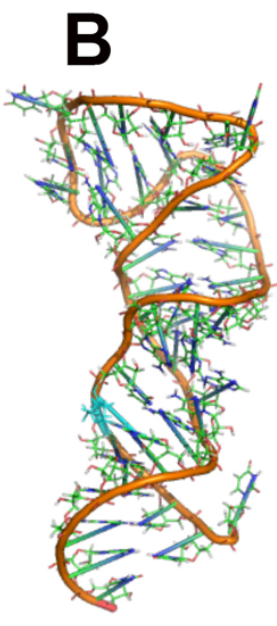

S2M SARS-COVs

MFE

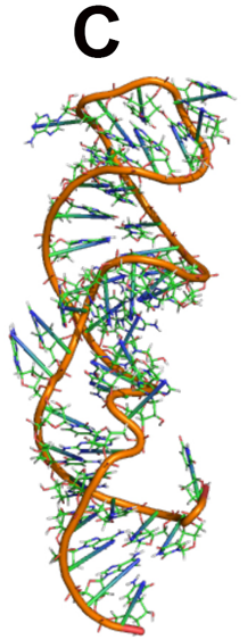

S2M SARS-COV2

MFE
D

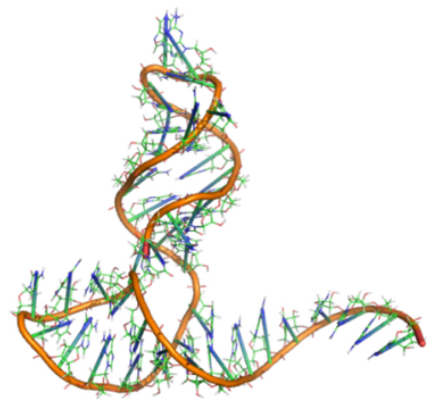

S2M SARS-COV2n

MFE

Figure 4. Tertiary structures of SARS-CoV-2 S2M RNA. Phylogenetic comparisons of S2M sequences from (a) Bat/Pangolin coronaviruses, (b) Human coronavirus MFE structure and (c,d) Human coronavirus canonical structure. 


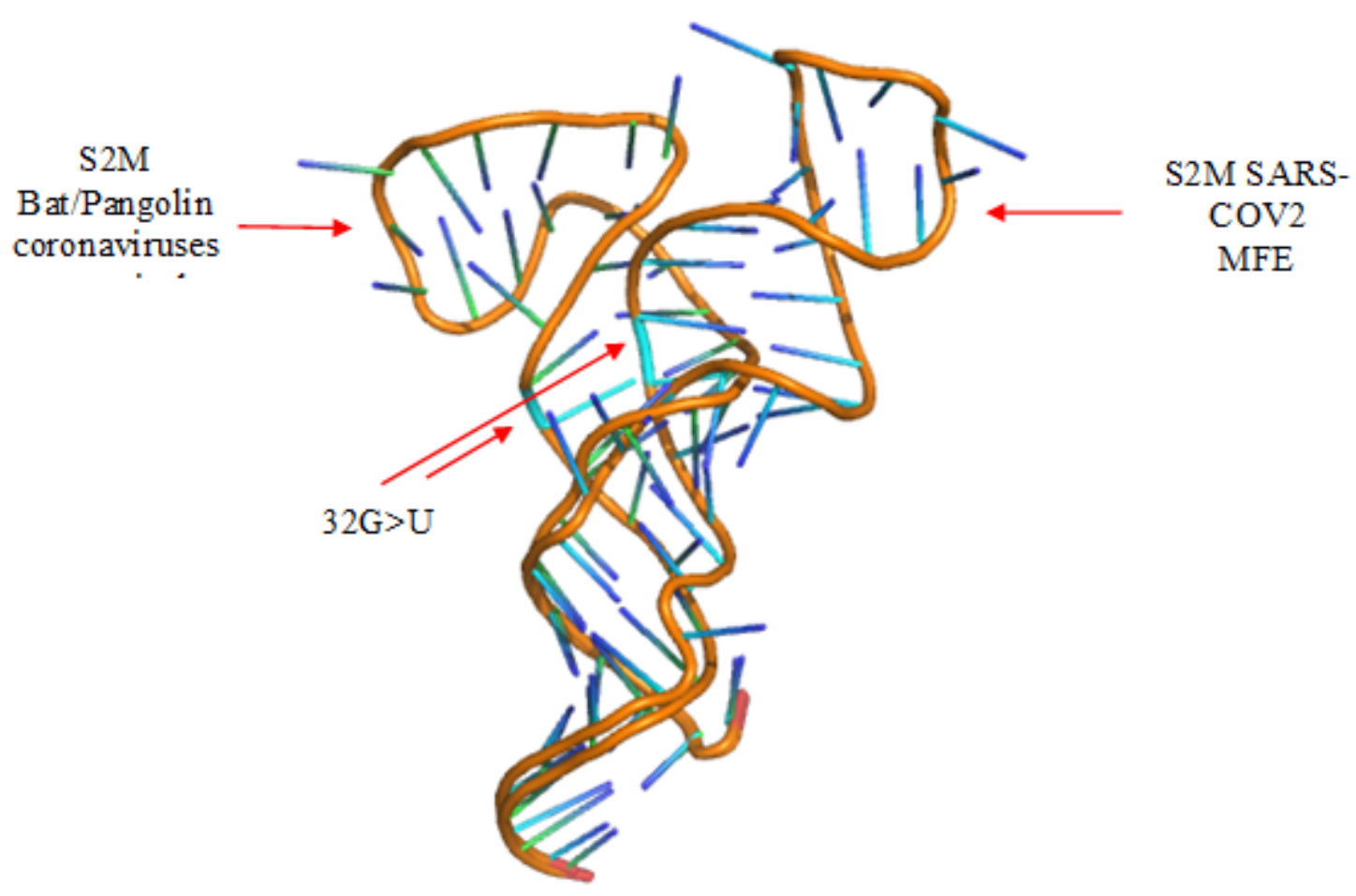

Figure 5. Superposition of tertiary structures of SARS-CoV-2 S2M RNA from bat and pangolin coronaviruses and human coronavirus MFE structure. 
(a)
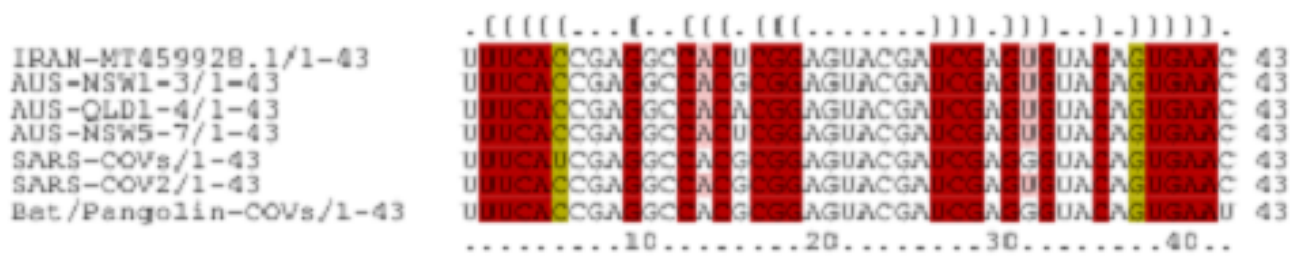

(b)

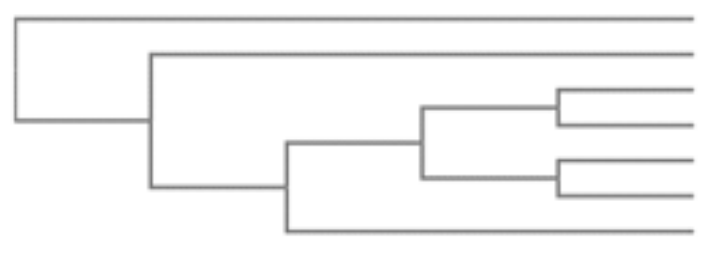

Bat/Pangolin-COVs 0.0276163

SARS-COVs 0.0319767

IRAN-MT459928.10

AUS-NSW5-70

AUS-NSW1-30

SARS-COV 20

AUS-QLD1-4 0.0116279

Figure 6: Coronavirus S2M sequence motifs. (a) Alignment of stem-forming elements and columns for each genotype for sequence representation and stem-loop structure representation. Lines above the alignment indicate stem-forming elements. Columns with Watson-Crick pairing changes for nucleotide positions have been color-coded. (b) ClustalW multiple sequence alignment trees display of coronavirus. 
bioRxiv preprint doi: https://doi.org/10.1101/2020.09.02 280529. this version posted September 8,2020 . The copyright holder for this preprint (which was not certified by peer review) is the author/funder, who has granted bioRxiv a license to display the preprint in perpetuity. It is made available under aCC-BY-ND 4.0 International license.

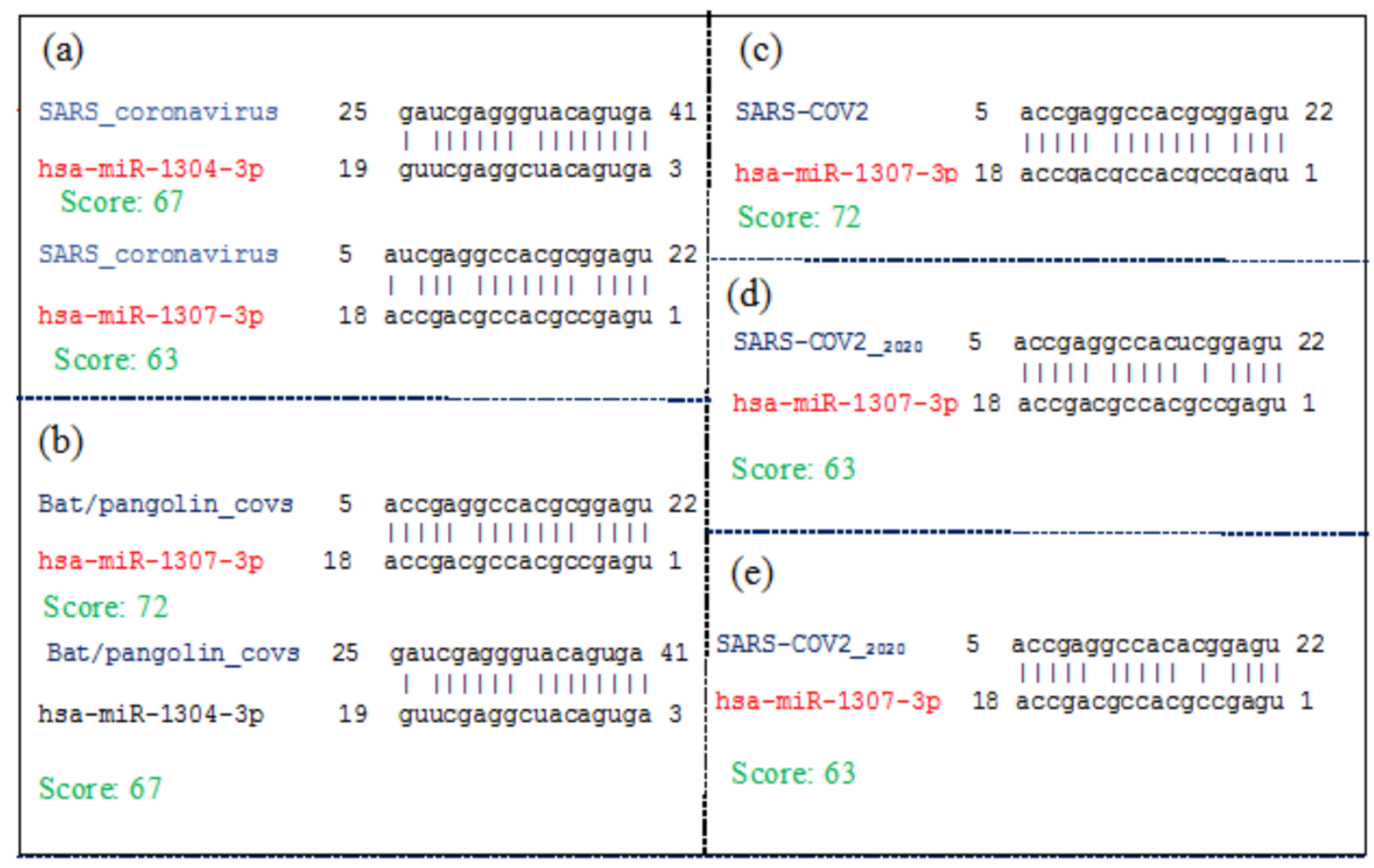

Figure 7: The predicted human miRNA binding sites within different regions of S2M sequences.

(a) miRNA binding sites within the S2M of SARS-CoV-1 (b) Bat/pangolin coronavirus. (c, d, e) The miRNA binding sites within the S2M of SARS-CoV-2. 
bioRxiv preprint doi: https://doi.org/10.1101/2020.09.02.280529; this version posted September 8, 2020. The copyright holder for this preprint (which was not certified by peer review) is the author/funder, who has granted bioRxiv a license to display the preprint in perpetuity. It is made available under aCC-BY-ND 4.0 International license.

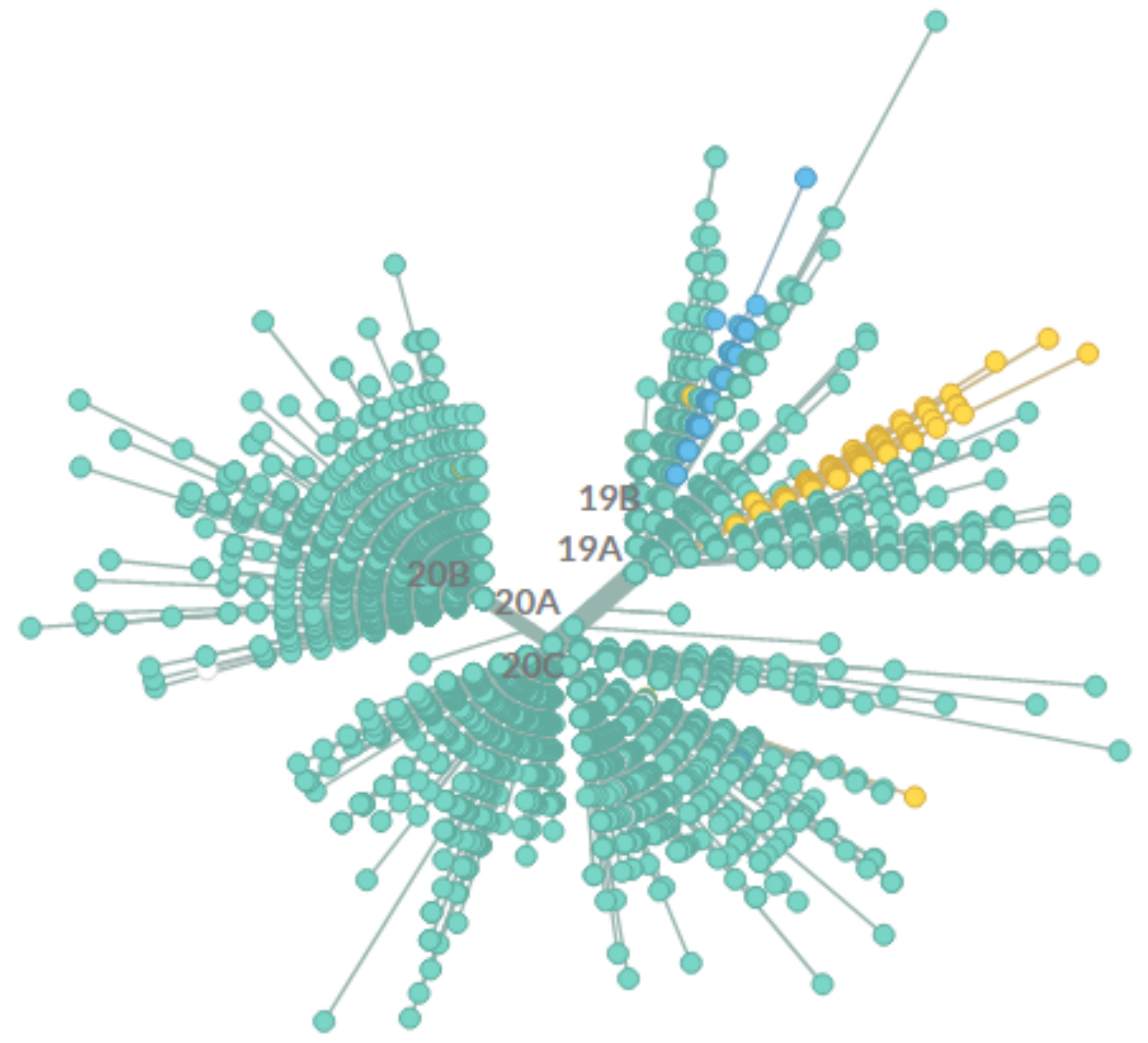

Figure 8: The position of conserved mutations in a phylogenetic graph obtained from

Nextstraindatabase. Picture captured on August 14st, 05: 17 AM. 
bioRxiv preprint doi: https://doi.org/10.1101/2020.09.02.280529; this version posted September 8, 2020. The copyright holder for this preprint (which was not certified by peer review) is the author/funder, who has granted bioRxiv a license to display the preprint in perpetuity. It is made available under aCC-BY-ND 4.0 International license.

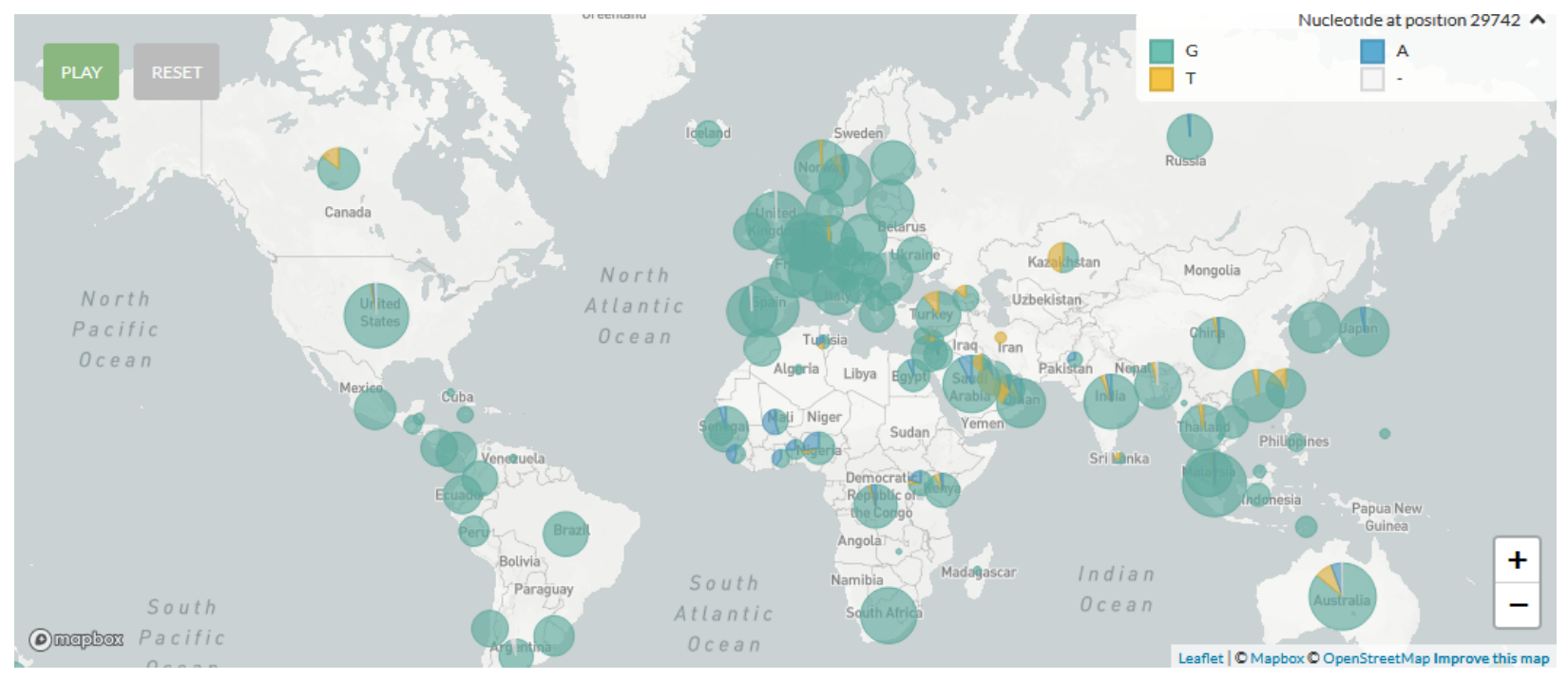

Figure 9: Geographical map of SARS-CoV-2 at position 29742 (S2M (16)). 